\title{
Does Critical Period Affect Bilingual Advantage for Working Memory and Metacognition?
}

\author{
Kexuan Huang ${ }^{1}$ \\ ${ }^{1}$ Concord Academy, Concord, MA 01742, USA \\ Correspondence: Kexuan Huang, Concord Academy, Concord, MA 01742, USA. E-mail: \\ kexuan.huang@concordacademy.org
}

Received: September 7, 2020 Accepted: October 10, 2020 Online Published: October 23, 2020

doi:10.5539/jel.v9n6p1 URL: https://doi.org/10.5539/jel.v9n6p1

\begin{abstract}
There have been many studies exploring the advantages that bilingualism confers to individuals' working memory and metacognition (see Ransdell, 2006; Del Missier et al., 2010). The hypothesis of language critical period states that if no language learning and teaching happen during the critical period, an individual will never be able to fully grasp any language to a full extent (Fromkin et al., 1974). This study investigates whether late bilingualism (second language acquisition after the critical period) will positively affect a person's working memory and metacognition just like early bilingualism (second language acquisition before the critical period) does. Sixty Chinese persons between the ages of 18 and 35 participated in my online experimental protocol, including a language experience questionnaire, a reading comprehension exam, and a reading span task. I found that late bilingualism poses a similar advantage to an individual's working memory as early bilingualism, while it negatively affects an individual's metacognitive awareness of their own language ability.
\end{abstract}

Keywords: bilingualism, critical period, working memory, metacognition

\section{Introduction}

Working memory uses information temporarily stored in a person's brain to perform cognitive tasks such as reasoning, comprehension, and learning. A part of short-term memory, working memory engages components of the cognitive system linked to perception and action (Baddeley, 1983). Working memory is one of three functions (with inhibition and shifting) considered collectively fundamental components of the brain's executive function. In recent decades, studies have shown a bilingual advantage in executive function: mastering two languages while speaking enhances one's cognitive flexibility (Yang, 2017).

One method researchers use to measure a person's working memory is the reading span (RS) test (Daneman \& Carpenter, 1980; Daneman \& Merikle, 1996). RS gauges a participant's ability to read a series of sentences and remember the final words of each sentence for later recall. As Whiteney et al. suggested in their 2001 study, how well an individual performs on the RS test depends on one's "manipulation capacity" and "susceptibility to interference" (Whitney et al., 2001). Bilingual individuals, because of their experiences in navigating two language systems - constantly activating, inhibiting, and switching between language codes - excel at RS which requires attention control and ignoring useless information, even in a monolinguistic context (Bialystok, 2007; Ransdell, 2006).

Metacognition signifies a person's awareness of their own cognitive ability. Researchers examine metacognitive accuracy by comparing a person's self-assessment of a language skill with an observer's assessment of that person's skill (Ross, 1998; Ransdell, 2006). Bilingual communicators tend to be more accurate in self-assessment than their monolingual peers (Ransdell, 2006; Soleimani \& Rahmanian, 2018). Since bilingual individuals' attention is regularly shifting while speaking different languages, they can judge their facility with a language more precisely, as demonstrated in Del Missier's test to examine participants' ability to apply decision rules and provide probability judgements for risky events (2010). In addition, bilingual communicators typically recognize asymmetry in their skill, identifying a higher degree of comfort with one language than the other (Whaley, personal communication). Both factors contribute to enhanced metacognition in bilingual individuals compared to monolingual individuals.

However, these prior studies demonstrating bilingual advantages in working memory and metacognition focus on 
people who started learning a second language before the age of 12 , an age which most linguists consider the upper age limit for a language critical period (Paradis, 1999; Munoz \& Singleton, 2011; Whaley, Personal Communication). This "critical period" refers to a period of time in an individual's cognitive development in which language learning must occur to ensure that individual's potential to fully understand how to use any language. During this period of cognitive development, an individual's neural circuits have not been fully specified, which leaves that person extremely sensitive to outside stimulus like language, making this cognitive period an individual's most promising opportunity to learn languages. Neural circuits continue to stabilize language input until they reach the end of the critical period (Kral \& Eggermont, 2007; Kuhl et al., 2008; White et al., 2013). This was the case for Genie, a girl who was deprived of all social interaction until she was found by police at the age of 13 years and 9 months (Fromkin et al., 1974). Though Genie was able to learn some English during her time at the hospital after her rescue, it was extremely difficult for Genie to think about language on a meta level (i.e., using language to talk about language); therefore, she apparently could not understand complex grammatical structures such as the negative movement transformation in which a language user moves a negative element from the beginning of a sentence to after a verb (for example, I can go in its negative form is transformed from Neg $+I+c a n+g o$ to $I+c a n+n e g($ can't) + go) (Fromkin et al., 1974).

While the case of Genie remains compelling, research in the 21 st century has demonstrated that cortical functions remain flexible throughout one's life span (Reuter-Lorenz, 2002; Bialystok, 2007). Studies by Reuter-Lorenz (2002) and Bialystok (2007) concluded that basic cognitive functions and neurological structures are susceptible to changes as a result of experiences and exposure. These modifications appear especially prominent in attentional processing. Reuter-Lorenz and Bialystock seem to challenge critical period theory in their assessment that cognitive and neurological development continues in response to life experience. To reconcile this difference, we must assess the role that critical period plays in affecting the cognitive and metacognitive advantages of bilingualism.

\section{Research Question and Hypothesis}

This study aims to investigate whether late bilingualism - that is, acquiring facility with a second language after the end of the critical period-positively affects a person's working memory and metacognitive awareness in a similar way to early bilingualism - acquisition of a second language before the critical period. I hypothesize that the effect of late bilingualism on cognition and metacognition will be positive, just like early bilingualism.

\section{Method}

\subsection{Participants}

Sixty Chinese from Shenzhen, China participated in my experiment online. Participants between the ages of 18 and 35 were selected for the likelihood of demonstrating strong working memory (Salthouse \& Babcock, 1991). Of all participants, 20 were monolingual (10 male, 10 female); 20 were early bilingual (10 male, 10 female), individuals that began to learn a second language before the age of 12 (on average, they began learning at 6.4 years old); and 20 were late bilingual ( 10 male, 10 female), subjects that began to learn a second language after the age of 12 (on average, they started learning at 14.1 years old). The qualifications for speaking a second language will be explained in the next section. All participants listed Mandarin as their native language. All early bilingual participants listed English as their second language. Of the 20 late bilingual participants, $75 \%$ listed their second language as English, 5\% listed Japanese, 5\% listed French, 5\% listed Russian, 5\% listed German, and 5\% listed Arabic. None of the participants spoke a third language, or any Chinese dialect.

Of the 60 participants, $66.7 \%$ were college students (who attended different colleges), while the remaining third held a variety of jobs, ranging from doctor to customer service representative. Participants were not all students due to difficulty of finding college students who are monolingual in China. Of the 41 college students, $41.5 \%$ of them had study-abroad experience. All participants came from middle-class families. All were experienced laptop users and performed the tasks for the study on their laptops.

Each participant was given 30 renminbi after completing the study.

\subsection{Materials and Procedure}

Experiments were conducted in July 2020. The first task was a Language Experience Questionnaire, in Mandarin, adapted from Ransdell et al. (2006, see Appendix A ). In the questionnaire, participants could put down a second language only if they believed they could live happily in a place where only that language is spoken for seven days. By posing the question this way, I aimed to assess the participants' comfort and satisfaction with their use of their second language. The questionnaire was made using wjx.cn and was sent to the participants via WeChat, a social media platform widely used in China. Participants were told that their responses would be confidential, and all 
participants were asked to complete the questionnaire by themselves when it was convenient for them.

Upon completion of the questionnaire, participants were sent via WeChat a reading comprehension exam in Mandarin, created with wjx.cn. The exam was adapted from the National College Entrance Examination in China (NCEE), or Gaokao $(2018,2019)$. None of the participants had previously taken the NCEE in 2018 or 2019. Each participant received, accompanying the exam, a message in Mandarin saying: "This is the reading comprehension exam in Mandarin, which includes three reading passages and nine multiple choice questions. Adapted from Gaokao, the exam is rather difficult; therefore, please open the link ONLY WHEN YOU ARE READY. The exam is timed, but you have as much time as you need to finish it. Thank you."

Finally, a reading span (RS) test in Mandarin was conducted for each participant. The RS test was adapted from Hannon and Daneman (2001) and Ransdell et al. (2006). All of the RS tests were conducted via the Tencent Meeting application, a Chinese online meeting platform similar to Zoom, in order to accommodate physical requirements mandated in response to the COVID-19 pandemic in 2020. Participants were instructed that both they and the researcher would leave cameras turned off but microphones on for the entire RS session. The participants were also instructed to schedule their meetings with the researcher at a time when they would be in a quiet space with a good internet connection; internet connections were double-checked once participants connected to Tencent Meeting. After connecting, the researcher shared her screen with a slide show and read the following instructions in Mandarin to the participants as displayed on the opening slide: "In this task, you will be presented with three series of sentences. Within each series, there are five sets of sentences, with each set on a separate Powerpoint slide. The sets within each series contain 2, 3, 4, 5, and 6 sentences, in increasing order. Please read these sentences out loud at your own pace. There is no connection between these sentences; half of these sentences don't even make sense. Please continue reading, without pausing, until you see a black screen with "STOP," indicating that this series is over. Your task is to remember the last two characters of each sentence while reading. The last two Mandarin characters won't be randomly combined in these sentences; they make up a word. You will be asked to recall the last two characters (or the last word) of each sentence after each trial is over. You can say them in any order, but you should not start with the last word first, unless it is the only one you can remember." Participants were then offered the opportunity to ask questions. After this, each participant completed a practice trial so that the participants could grasp the concept of the task. They then began three evaluated trial sets. The researcher recorded every word (or last two characters) that each participant stated correctly. Sentences within sets were written to be unrelated to each other; some were constructed to not make sense, in order to prevent cases where participants could easily recall the final words because of strong conceptual connections between sentences. 


\section{Results}

\subsection{Working Memory}

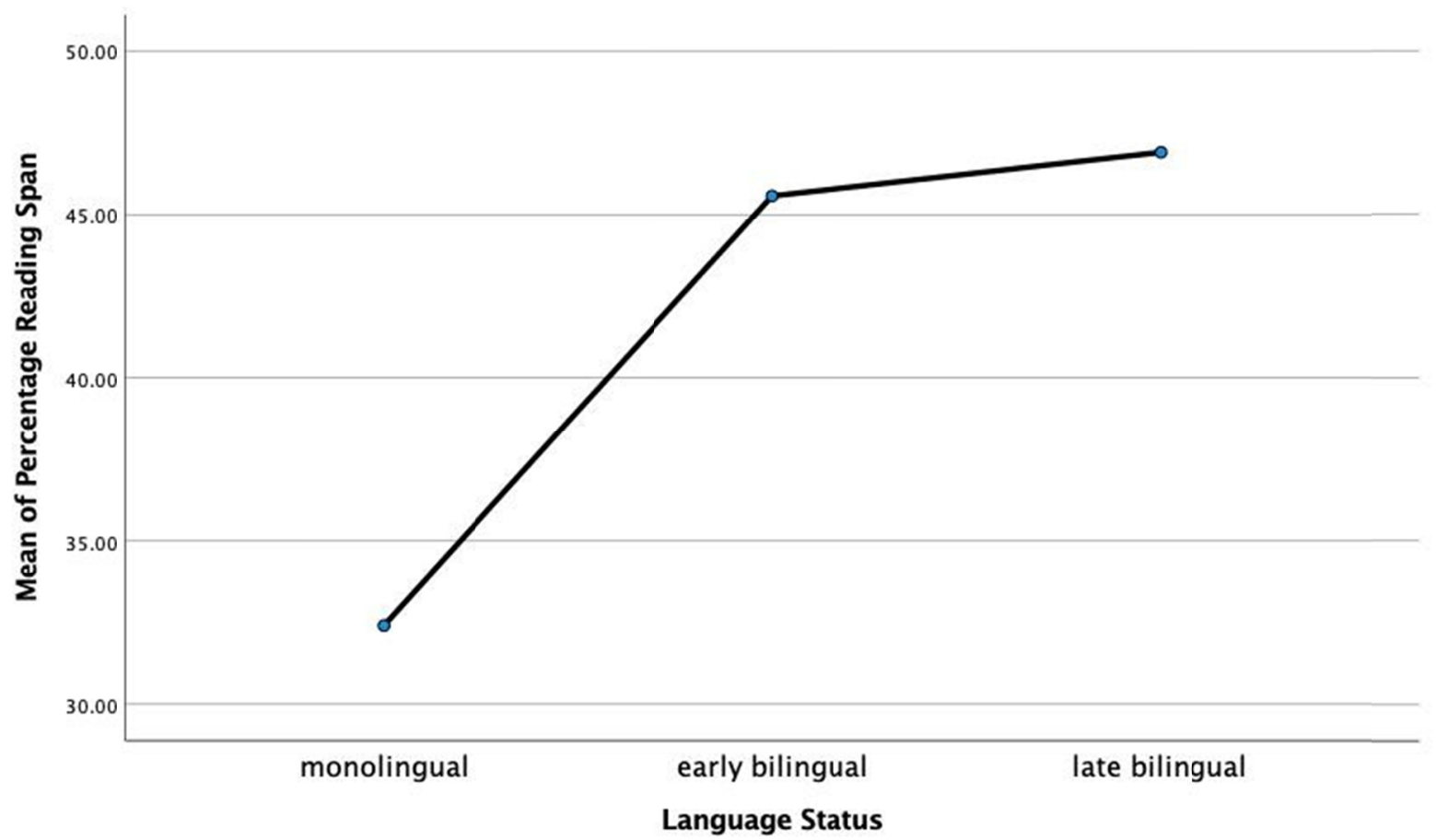

Figure 1 . The percentage of final words recalled among monolinguals, early bilinguals, and late bilinguals

The mean percentage of correct responses for monolingual subjects $(M=32.42, S D=18.40,95 \% \mathrm{CI}$ : [23.81, 41.06]) is significantly lower than that of early bilingual subjects $(M=45.5833, S D=14.25,95 \% \mathrm{CI}$ : [38.92, $52.25])$ and late bilingual subjects $(M=46.92, S D=6.74,95 \% \mathrm{CI}$ : [37.10, 46.17]), $F(2,57)=4.690, p=0.013)$. There is no significant difference between the results of early bilingual participants and late bilingual participants, $p=0.965$.

\subsection{Metacognition}

Table 1. Summary of linear regression analysis for self-assessment predicting reading comprehension scores $(\mathrm{N}=$ 60)

\begin{tabular}{llll}
\hline Regressor & 1 & 2 & 3 \\
\hline Constant & $3.103^{*}$ & $1.843^{*}$ & $9.905^{*}$ \\
Self-Assessment & 0.361 & $0.788^{* *}$ & $-1.223^{*}$ \\
$\mathrm{~F}$ & 0.824 & 10.221 & 4.503 \\
Mean Square & 2.476 & 29.319 & 13.397 \\
$\mathrm{R}$ & 0.209 & 0.602 & 0.447 \\
$\mathrm{R}^{2}$ & 0.044 & 0.362 & 0.200 \\
Numbers of Observation & 20 & 20 & 20 \\
\hline
\end{tabular}

Note. ${ }^{*} p<0.05 ;{ }^{* *} p<0.01$.

1) For monolingual individuals, data indicate no significant relationship between self-assessed scores for reading comprehension and researcher-assessed reading comprehension scores $(F(1,18)=0.824, p=0.376)$.

2) For early bilingual participants, Reading Comprehension Score $=1.843+0.788 *$ Self-Assessment $(F(1,18)=$ $10.22, p=0.005$ ). Data suggest a positive correlation between self-assessment of Mandarin reading skills and researcher-assessed reading comprehension scores. 
3) For late bilingual subjects, Reading Comprehension Score $=9.905-1.223^{*}$ Self-Assessment $(F(1,18)=4.50, p$ $=0.048$ ). Data indicate a negative correlation between participants' self-assessment scores of Mandarin reading skills and researcher-determined reading comprehension scores.

\subsection{RS and Reading Comprehension}

Findings suggest no significant correlation between RS scores and Reading Comprehension scores for monolingual participants $(F(1,18)=0.66, p=0.43)$, early bilingual participants $(F(1,18)=0.79, p=0.39)$, and late bilingual participants $(F(1,18)=3.15, p=0.09)$.

\subsection{Reading Comprehension}

One-way analysis of variance (ANOVA) identifies no significant difference between the reading comprehension scores of the three groups $(F(2,57)=1.17, p=0.32)$. One-way ANOVA shows no significant difference between the time taken for reading comprehension for the three groups $(F(2,57)=0.14, p=0.87)$. Linear regression analysis shows that reading comprehension time does not correlate with reading comprehension scores for monolingual participants $(F(1,18)=0.17, p=0.68)$, early bilingual participants $(F(1,18)=0.10, p=0.76)$, and late bilingual participants $(F(1,18)=0.15, p=0.71)$.

\subsection{Other Factors}

Linear regression analysis shows that gender has no effect on Reading Span test results $(F(1,58)=0.07, p=0.93)$, reading comprehension scores $(F(1,58)=2.72, p=0.11)$, or on self-assessment $\operatorname{scores}(F(1,58)=3.20, p=0.079)$.

\section{Discussion and Conclusion}

My experiments show that early bilingual subjects and late bilingual subjects show more accurate working memory than their monolingual peers, as demonstrated by reading span test results $(p=0.013)$. However, there is no significant difference between the working memory of early bilingual participants and that of late bilingual participants $(p=0.965)$. Despite studies showing that late bilingual subjects are unable to reach a native level in their second language unless relying on "explicit, analytic, problem-solving capacities" (DeKeyser, 2000; Bley-Vroman, 1988), the present research suggests that the critical period does not interfere with the cognitive advantage that bilingualism confers to individuals. This might be explained by Bialystok's 2007 findings that neurological plasticity continues for a period of time beyond the critical period in cognitive processing such as attentional processing. The RS working memory test requires attention control as participants attempt to focus on only the final words when reading an entire sentence. Whether one is early bilingual or late bilingual, the daily practice of inhibiting one language while speaking another empowers bilingual communicators to pay attention to language codes and exercise their short-term memory in a distinct way that monolingual individuals do not in their daily lives. It may follow that late bilingual individuals might even yield better results on the RS test, since they would, presumably, be consciously working harder in this process; although a higher mean for late bilingual participants' RS score compared to that of early bilingual participants was observed, the difference is not statistically significant.

Results also demonstrate a positive correlation between self-assessment scores and reading comprehension scores for early bilingual participants, and no correlation between self-assessment scores and reading comprehension scores for monolingual participants. Most surprisingly, there was a negative correlation between the self-assessment scores and reading comprehension scores for late bilingual subjects. This suggests that the theory that bilingual communicators judge more appropriately in general (Del Missier et al., 2010) only applies to early bilingual individuals. A possible explanation as to why late bilingual individuals tend to overestimate their language facility is that they have been speaking their native language for a longer period of time and would be uncomfortable with the idea that they are losing fluency in their native language. This has been observed in native speakers of Oroqen, an endangered language. Subjects were late bilingual learners of Mandarin that overrated their Oroqen ability, likely due to expectations individuals felt to be able to speak their heritage language well (Whaley, personal communication).

My analysis found no significant difference between the reading comprehension scores of the three groups $(F(2$, $57)=1.171, p=0.317$ ), which is consistent with other studies that compare the reading ability of bilingual and monolingual readers (for example, Ransdell, 2006). One might argue that bilingual participants would perform better in reading comprehension since they are able to inhibit language code effectively, thus inhibiting useless information when reading in a similar way. However, individuals demonstrate significant variation in reading comprehension ability due, possibly, to external environmental factors such as schooling and family. In addition, since the reading comprehension was completed in Mandarin, bilingual subjects who have studied abroad may have been less comfortable in this task than monolingual participants educated in Mandarin for their entire 
academic careers. Therefore, it would be unreasonable to compare the reading comprehension results of the three groups and expect there to be a difference.

Many confounding variables may confound study of bilingual individuals. One way I tried to eliminate confounding factors in this study was to correlate RS scores with reading comprehension scores. As shown in the Results section, the linear regression analysis for monolingual individuals, early bilingual persons, and late bilingual subjects shows no correlation between RS and reading comprehension scores. A positive result of this analysis may have indicated that factors other than bilingualism inform findings, factors like the likelihood that certain people are particularly adept at certain tasks in this experimental protocol. I attempted through linear regression analysis to ensure that gender and time taken to complete the reading comprehension task did not affect findings (see Results section).

However, certain factors limited this study. Participants were not all from one college or institution and may not have received uniform training in working memory and metacognition during their academic careers. Furthermore, it is possible that the participants did not fully demonstrate their metacognitive ability; research has shown that participants' level of motivation to complete a task, as well as their emotional state while conducting tested tasks, may impact metacognition test results (Bryce, 2015). Finally, each participants' degree of comfort with completing tasks on a computer may have varied, though most participants had previous experience with remote learning and working, given the circumstances of the 2020 COVID-19 pandemic.

The present study is, to the best of my knowledge, the first that examines the effects of the critical period on cognitive advantages experienced by bilingual individuals compared to their monolingual peers. It may have important implications for second-language learning, suggesting that it's never too late, in terms of cognitive capacities of working memory, to learn a second language. It also suggests educators, employers, and late bilinguals may wish to keep in mind a tendency to overrate their (late bilinguals') language facility.

Future research should focus on assessing a larger sample size, as well as designing experiments to examine how anxiety over losing proficiency in one's native language contributes to inflated assessment of one's reading comprehension skills in the primary language.

\section{References}

Baddeley, A. D. (1983). Working Memory. Philosophical Transactions of the Royal Society of London. Series B, Biological Sciences, 302(1110), 311-324. https://doi.org/10.1098/rstb.1983.0057

Baddeley, A. D., \& Hitch, G. J. (1974). Working memory. The Psychology of Learning and Motivation, 8, 47-90. New York: Academic Press. https://doi.org/10.1016/S0079-7421(08)60452-1

Bialystok, E. (2007). Cognitive Effects of Bilingualism: How Linguistic Experience Leads to Cognitive Change. International Journal of Bilingual Education and Bilingualism, 10(3), 210-223. https://doi.org/10.2167/beb441.0

Bley-Vroman, R. (1988). The fundamental character of foreign language learning. In W. Rutherford \& M. Sharwood Smith (Eds.), Grammar and second language teaching: A book of readings (pp. 19-30). Rowley, MA: Newbury House.

Bryce, D., Whitebread, D., \& Szucs, D. (2015). The relationships among executive functions, metacognitive skills, and educational achievement in 5 and 7-year-old children. Metacognition and Learning, 10(2), 181-198. https://doi.org/10.1007/s11409-014-9120-4

Daneman, M., \& Carpenter, P. A. (1980). Individual differences in working memory and reading. Journal of Verbal Learning and Verbal Behavior, 19, 450-466. https://doi.org/10.1016/S0022-5371(80)90312-6

Daneman, M., \& Merikle, P. M. (1996). Working memory and language comprehension: A meta-analysis. Psychonomic Bulletin and Review, 3, 422-433. https://doi.org/10.3758/BF03214546

DeKeyser, R. (2000). The robustness of critical period effects in second language acquisition. Studies in Second Language Acquisition, 22(4), 499-533. https://doi.org/10.1017/S0272263100004022

Del Missier, F., Mäntylä, T., \& Bruine de Bruin, W. (2010). Executive functions in decision making: An individual differences approach. Thinking \& Reasoning, 162, 69-97. https://doi.org/10.1080/13546781003630117

Fromkin, V. et al. (1974). The Development of Language in Genie: A Case of Language Acquisition beyond the 'Critical Period.' Brain and Language, 1(1), 81-107. https://doi.org/10.1016/0093-934X(74)90027-3

Hannon, B., \& Daneman, M. (2001). A new tool for measuring and understanding individual differences in the 
component process of reading comprehension. Journal of Educational Psychology, 93(1), 103-128 https://doi.org/10.1037/0022-0663.93.1.103

Kral, A., \& Eggermont, J. J. (2007). What's to lose and what's to learn: development under auditory deprivation, cochlear implants and limits of cortical plasticity. Brain Research Reviews, 56, 259-269. https://doi.org/10.1016/j.brainresrev.2007.07.021

Kuhl, P. K., Conboy, B. T., Coffey-Corina, S., Padden, D., Rivera-Gaxiola, M., \& Nelson, T. (2008). Phonetic learning as a pathway to language: new data and native language magnet theory expanded (NLM-e). Philosophical Transactions of the Royal Society of London. Series B, Biological Sciences, 363(1493), 979-1000. https://doi.org/10.1098/rstb.2007.2154

Muñoz, C., \& Singleton, D. (2011). A critical review of age-related research on L2 ultimate attainment. Language Teaching, 44, 1-35. https://doi.org/10.1017/S0261444810000327

Paradis, M. (1999). Neurolinguistic aspects of bilingualism (pp. 59-60). Amsterdam: J. Benjamins.

Ransdell, S., Barbier, M., \& Niit, T. (2006). Metacognitions about Language Skill and Working Memory among Monolingual and Bilingual College Students: When Does Multilingualism Matter? International Journal of Bilingual Education and Bilingualism, 9(6), 728-741. https://doi.org/10.2167/beb390.0

Reuter-Lorenz, P. A. (2002). New visions of the aging mind and brain. Trends in Cognitive Science, 6, 394400. https://doi.org/10.1016/S1364-6613(02)01957-5

Ross, S. (1998). Self-assessment in second language testing: A meta-analysis and analysis of experiential factors. Language Testing, 15, 1-20. https://doi.org/10.1177/026553229801500101

Salthouse, T. A., \& Babcock, R. L. (1991). Decomposing Adult Age Differences in Working Memory. Developmental Psychology, 27(5), 763-776. https://doi.org/10.1037/0012-1649.27.5.763

Soleimani, H., \& Rahmanian, M. (2018). The Effect of Bilingualism and Trilingualism on Metacognitive Processing: Detrimental or Beneficial? Journal of Psycholinguistic Research, 47, 803-815. https://doi.org/10.1007/s10936-018-9563-x

White, E. J. et al. (2013). Learning, Neural Plasticity and Sensitive Periods: Implications for Language Acquisition, Music Training and Transfer across the Lifespan. Frontiers in Systems Neuroscience, 7. https://doi.org/10.3389/fnsys.2013.00090

Whitney, P., Arnett, P. A., Driver, A., \& Budd, D. (2001). Measuring central executive functioning: What's in a reading span? Brain and Cognition, 45, 1-14. https://doi.org/10.1006/brcg.2000.1243

Yang, E. (2017). Bilinguals' Working Memory (WM) Advantage and Their Dual Language Practices. Brain Sciences, 7(7), 86. https://doi.org/10.3390/brainsci7070086

\section{Appendix A}

\section{Language Experience Questionnaire (translated from Mandarin)}

All responses are coded by subject ID only.

Country of Origin

Parents' Countries of Origin

Age

Sex

Native Language

Second Language (if applicable) (the standard of being able to speak a second language is: to be able to live happily in a place where only that language is spoken for seven days)

Since when have you been learning your second language

Third Language (if applicable)

In comparison to other Chinese of a similar age as you, what is your level of reading in Mandarin from a scale of 1 to 5 ? 


\section{Copyrights}

Copyright for this article is retained by the author, with first publication rights granted to the journal.

This is an open-access article distributed under the terms and conditions of the Creative Commons Attribution license (http://creativecommons.org/licenses/by/4.0/). 